\title{
MÉTODO DIDÁTICO: DEMONSTRAÇÃO PRÁTICA DA EFICIÊNCIA DA LAVAGEM DE EMBALAGENS VAZIAS DE AGROTÓXICOS
}

\author{
PAVARINI, Gláucia Maria Pereira ${ }^{1}$
} PAVARINI, Ronaldo ${ }^{1}$

\begin{abstract}
RESUMO: Segundo o Decreto $N^{\circ} 4.074$ (04/01/2002), que regulameta a Lei de Agrotóxicos (Lei 7802/89), as embalagens rígidas de agrotóxicos que contiverem formulações miscíveis ou dispercíveis em água deverão ser submetidas pelo usuário à operação de tríplice lavagem, ou tecnologia equivalente, conforme normas técnicas oriundas dos órgãos competentes e orientação constante de seus rótulos e bulas. Entretanto, muitas vezes é preciso realizar a demonstração da eficiencia desta operação em ambientes não trabalhistas, como feiras, escolas, salas de aulas, dentre outras. Nestes casos, não é recomendável que se utilize embalagens contendo agrotóxicos. Desta forma, foi desenvolvido um método que utiliza um traçador que representa de maneira bem realística o que ocorre na prática. Com este método é possível demonstrar os procedimentos corretos de como se deve realizar a tríplice lavagem de embalagens vazias de agrotóxicos e quais suas vantagens. O método permite, de forma segura, a constatação visual e quantitativa da porcentagem do traçador que é retirada destas embalagens através do procedimento da tríplice lavagem e demonstra ao usuário a necessidade e vantagens em se realizar este procedimento logo após o término do esvaziamento da embalagem e com o máximo de cuidado possível.
\end{abstract}

Palavras-chave: Embalagens de agrotóxicos. Tríplice lavagem. Retirada de resíduos.

\section{TEACHING METHOD: STATEMENT OF PRACTICE EFFICIENCY OF LAUNDERING EMPTY PESTICIDE CONTAINERS}

\begin{abstract}
SUMMARY: According to Decree No. 4074 (04/01/2002) that regulates Pesticide Law (Law 7802/89), the rigid containers of pesticides with water-miscible or dispersiveness formulations must be submitted by the user to the operation of triple-rinsing or equivalent technology, as coming from technical standards and constant guidance of their labels and package inserts. However, it is often necessary to perform the demonstration of the efficiency of this operation in non-labor, such as fairs, schools, classrooms, among others. In these cases, it is not recommended to use containers containing pesticides. Thus, we developed a method using a tracer that would represent quite realistic of what happens in practice. With this method its possibel to demonstrate the correct procedures of how to perform the triple rinsing of empty pesticide and its advantages. The method allows safely qualitative and quantitative viewing of the percentage of tracer that is removed from these containers by triple rinsing procedure and shows the user about the need and advantages to performing this procedure immediately after the emptying of the container and with the maximum care possible.
\end{abstract}

Keywords: Pesticide containers. Triple washing. Removal of waste.

\section{INTRODUÇÃO}

A aplicação de agrotóxicos em propriedades agrícolas é uma prática bastante antiga. Estes produtos são usados na agricultura para combater as plantações do ataque de pragas. As formulações de agrotóxicos devem ser acondicionadas em embalagens seguras e adequadas a cada tipo de produto.

Após o uso da formulação, as embalagens vazias, contaminadas com resíduo de agrotóxicos, devem ser descartadas de maneira correta e segura, sendo a forma recomendada, no Brasil, a tríplice lavagem (CHIQUETTI, 2005). Se este procedimento não for realizado, os resíduos químicos tóxicos presentes em embalagens de agrotóxicos e afins podem contaminar as pessoas que forem manipular estas

${ }^{1}$ Docentes da UNESP-Universidade Estadual Paulista “Júlio de Mesquita Filho”, Campus de Registro.

Nucleus, v.9, n.2, out.2012 
embalagens, além do que estes resíduos quando abandonados no ambiente ou descartados em aterros e lixões, sob ação da chuva, podem migrar para águas superficiais e subterrâneas, contaminando o solo e lençóis freáticos (IPT/CEMPRE, 2000). Para Moreira et al (2002), durante o processo de utilização dos agrotóxicos, o descarte de resíduos e embalagens contaminadas é uma das causas de contaminação das águas, através da migração de resíduos de agrotóxicos para lençóis freáticos, leitos de rios, córregos, lagos e lagunas próximos. Sugimoto (2005) ressalta que $61 \%$ das embalagens devolvidas contêm resíduos e que o descarte indevido das embalagens de agrotóxicos em rios, nas plantações ou mesmo nos aterros, acarretam graves problemas de poluição ambiental. A tríplice lavagem das embalagens, conforme recomendada na Lei 9974/00, antes do seu descarte, pode ser uma das práticas para a solução desse problema juntamente com a educação ambiental continuada sobre os perigos inerentes ao uso impróprio desses produtos (BARREIRA; PHILIPPI, 2002). Dados de trabalhos científicos realizados em laboratório indicam que a quantidade média de resíduo de uma embalagem esvaziada e não tríplice lavada é de aproximadamente $0,3 \%$ do conteúdo original (PRODUÇÃO RURAL, 2000).

A norma técnica de procedimento de lavagem de embalagem rígida vazia de agrotóxico é a NBR 13.968 (ABNT, 1997). Segundo dados relatados nesta norma, a embalagem rígida vazia não-perigosa será aquela que contiver formulações de agrotóxicos utilizáveis diluídas em água e que, submetidas aos adequados procedimentos de lavagem interna, apresentem na água de lavagem final uma concentração, em ingrediente ativo, do produto originalmente acondicionado, menor que $100 \mathrm{ppm}$. Isto será obtido por meio da realização da tríplice lavagem, que é comprovadamente eficaz na eliminação de resíduo de agrotóxico.

Portanto, os resíduos presentes na disposição pós-uso da embalagem de agrotóxicos é uma problemática a ser considerada. Assim, a tríplice lavagem das embalagens vazias de agrotóxicos, antes do seu descarte, torna-se, quando realizada de forma eficiente, uma das práticas para a solução desse problema para a maioria dos produtos acondicionados em embalagens plásticas rígidas.

Segundo o Decreto № 4.074 (04/01/2002), que regulamenta a Lei de Agrotóxicos (Lei 7802/89), as embalagens rígidas de agrotóxicos que contiverem formulações miscíveis ou dispercíveis em água deverão ser submetidas pelo usuário à operação de tríplice lavagem, ou tecnologia equivalente, conforme normas técnicas oriundas dos órgãos competentes e orientação constante de seus rótulos e bulas, pois cabe ao usuário preparar tais embalagens vazias para devolvê-las nas unidades de recebimento.

Toda embalagem rígida seja ela, metálica, plástica ou de vidro, e que acondicionarem formulações líquidas de agrotóxicos miscíveis ou dispersáveis em água, podem e devem ser submetidas à tríplice lavagem, isto é, enxaguadas internamente três vezes consecutivas, logo após o esvaziamento da embalagem, e as águas da lavagem vertidas no tanque do pulverizador. A tríplice lavagem de embalagens de agrotóxico deve ser realizada durante a operação de preparo de calda, na ocasião em que o conteúdo da embalagem é totalmente despejado no tanque do pulverizador. É importante salientar, a importância de se realizar a tríplice lavagem imediatamente após o esgotamento do produto contido na embalagem para facilitar a remoção, aproveitar ao máximo o conteúdo do líquido e evitar que o produto resseque e fique aderido nas paredes da embalagem, dificultando o processo de remoção dos resíduos internos. A tríplice lavagem é um processo simples, barato, eficiente e fácil de ser executado pelo próprio aplicador (CATARINACHO, s.d.).

Segundo Gerassi (1998), para realizar a tríplice lavagem das embalagens adequadamente, deve-se proceder da seguinte forma: inverta a embalagem sobre o tanque do pulverizador ou da vasilha de preparo da calda e deixe escorrer por, pelo menos, 30 segundos, até que as gotas pinguem em tempos espaçados; para permitir uma boa lavagem, adicione água na embalagem até atingir 1/4 de sua capacidade, ou seja, em uma embalagem de 1 litro adicione $250 \mathrm{~mL}$ de água. Feche bem a embalagem e agite por, pelo menos, 30 segundos em todos os sentidos. Despeje o conteúdo da água de lavagem no tanque do pulverizador.

Nucleus, v.9, n.2, out.2012 
Esta operação deverá ser repetida mais duas vezes. Perfure o fundo das embalagens plásticas e metálicas para evitar sua reutilização e use os equipamentos de proteção individual adequados.

Quando as embalagens rígidas laváveis de agrotóxicos são adequadamente tríplice lavadas, os riscos de contaminação humana, dos animais domésticos e de criação e do meio ambiente diminuem e aparecem os benefícios. Diversos autores descrevem as vantagens da tríplice lavagem como: uma técnica que assegura total aproveitamento do conteúdo da embalagem, uma vez que a calda resultante da lavagem é despejada no tanque e pulverizada na lavoura, além de não desperdiçar um produto que, geralmente, tem custo elevado, resultando em economia; após a tríplice lavagem a embalagem estará devidamente lavada e passível de destinação final e adequada, reduzindo significativamente os riscos para a saúde das pessoas e animais, eliminando o contato com embalagens contaminadas e praticamente os riscos de contaminação do ambiente: solo, água e seres vivos, além de permitir o encaminhamento das embalagens para os pontos de recebimento e viabilizar a reciclagem do material (AEASP, 1992; GERASSI, 1998; ZAMBOLIN et. al., 2003; PAVARINI, 2008; CATARINACHO s.d.).

Após serem esvaziadas, as embalagens de produtos fitossanitários normalmente retém quantidades variáveis de produto no seu interior, de acordo com a área de superfície interna, formato da embalagem e formulação (PRODUÇÃO RURAL, 2000).

Como decorrência da prática da tríplice lavagem (processo manual) ou lavagem sob pressão (processo mecânico), a remanescência de resíduos de produtos fitossanitários na água da terceira lavagem situa-se na faixa de fração de ppm (partes por milhão), o que caracteriza uma condição de absoluta segurança para as atividades posteriores como manuseio, transporte e armazenagem das embalagens vazias assim lavadas. Em países como Holanda e França, toda embalagem vazia tríplice lavada que apresente um resíduo líquido remanescente no seu interior inferior a $0,01 \%$ - o que corresponde a 100 ppm - é considerada rejeito comum. Estudos comprovaram que os níveis de resíduos encontrados no Brasil, na quarta água de lavagem, estão dentro dos parâmetros internacionalmente aceitos (CATARINACHO s.d.).

Segundo pesquisas realizadas por Evaristo (1993) e Baptista (1996) o procedimento da tríplice lavagem em embalagens de agrotóxicos produz resultados bastante positivos, garantindo mais de $99 \%$ de eficácia de remoção de resíduo de produto das embalagens. Através de resultados obtidos em laboratório, constatou que a tríplice lavagem mostra-se eficiente para a descontaminação de embalagens do produto glifosato quando realizada de forma correta (PRIOTTO, 2007).

O monitoramento das condições em que as embalagens estão sendo submetidas, nos postos ou centrais de recebimento, garante uma melhoria contínua no processo idealizado. Chiquetti (2005), verificou que embalagens devolvidas nos postos de recebimento continham resíduos de agrotóxicos remanescentes acima dos níveis desejados. Este fato foi atribuído a diversos motivos, e dentre eles, à prováveis descuidos dos operadores nos procedimentos realizados durante a tríplice lavagem destas embalagens ou mesmo por não visualizarem a necessidade de se realizar esta metodologia corretamente para obtenção de um resultado satisfatório.

Enfatiza-se assim a necessidade de conscientização da população em relação à tríplice lavagem em conformidade com a Norma NBR 13.968 (ABNT, 1997) e ao fato de entregar as embalagens vazias ao destino correto. Pereira; Galdiano (2004) ressaltam que para que tais informações sejam levadas ao homem do campo, é necessário um treinamento bem específico e didático, com aulas práticas, para melhor assimilação.

Neste contexto este trabalho teve como objetivo estabelecer um método didático que demonstre, de forma prática, a importância em se adotar os procedimentos corretos de como realizar a tríplice lavagem de embalagens vazias de agrotóxicos para ser utilizado em cursos de agronomia e afins, além de treinamentos de agricultores e demais pessoas envolvidas com o uso destes produtos, demonstrando 
qualitativamente e quantitativamente a eficiência da tríplice lavagem.

\section{MATERIAL E MÉTODOS}

A metodologia descrita a seguir foi elaborada, com finalidade de demonstrar, de forma didática e segura, para alunos, produtores e outras pessoas envolvidas com a área agrícola, os procedimentos corretos de como se deve realizar a tríplice lavagem de embalagens vazias de agrotóxicos e quais suas vantagens.

O método consiste em utilizar, no lugar do agrotóxico, a tinta látex de cor preta, para a realização do procedimento já consagrado da tríplice lavagem, a fim de demonstrar sua eficiência qualitativamente e quantitativamente, em aulas práticas e dias de campo.

\section{- Montagem de um kit didático para demonstração visual da eficiência da lavagem de embalagens vazias:}

O kit para avaliação qualitativa foi obtido pela diluição de um traçante de cor preta em água destilada e pelas águas de lavagens resultantes da simulação do completo esgotamento e da tríplice lavagem de uma embalagem contendo uma formulação contendo um traçante. Para tal utilizou-se um litro de tinta látex de cor preta, marca Suvenil (traçador) e uma embalagem plástica virgem de 1 litro vazia. A embalagem deverá ser de plástico, podendo ser de polietilieno de alta densidade (PEAD), polietileno coextruturado (COEX) ou politereftalato de etileno (PET), ou ainda de um outro tipo. Também foram utilizados 09 frascos de $100 \mathrm{~mL}$ com tampa, 4 frascos com tampa para acondicionar as águas de lavagem, micropipetas de 0 a $1000 \mathrm{uL}$, pipetas graduadas de 1, 5 e $10 \mathrm{~mL}, 1$ béquer graduado de $250 \mathrm{~mL}$, tecido de meia calça fina feminina, água deionizada e béquer de 5 litros.

Inicialmente, construiu-se uma curva com o traçador. Partindo da tinta látex pura, fez-se as seguintes diluições com água destilada: $100 \% ; 10 \% ; 5 \%, 1 \% ; 0,5 \% ; 0,1 \% ; 0,05 \% ; 0,01 \%$ e $0,001 \%$ (Figura 1-A). A concentração de $0,0 \%$ (água destilada) poderá também ser incluída.

Estas diluições foram colocadas em frascos de vidros bem vedados e de preferência pequenos, para facilitar no manuseio. Utilizou-se frascos de $100 \mathrm{~mL}$ com tampas de rosca.

Paralelamente, a isto colocou-se, $1 \mathrm{~L}$ de látex preto em uma embalagem limpa (embalagem virgem) e aguardou-se 24 horas. Este recipiente contendo a tinta fresca, representou a embalagem contendo o agrotóxico e que foi posteriormente esvaziado e submetido ao procedimento da tríplice lavagem. A embalagem contendo a tinta foi completamente esgotada em um béquer de 5 litros, o qual simulava um pulverizador costal manual, durante o preparo de uma calda no campo.

Após as 24 horas, realizou-se a tríplice lavagem. Ao fazer este procedimento, descartou-se parte da água no pulverizador costal (béquer 5L) e parte dela em um frasco limpo etiquetado com os dizeres "Água da $1^{\text {a }}$ Lavagem". Repetiu-se isto na segunda e terceira lavagem, armazenando parte do volume da água em frascos etiquetados (Figura 1-B). Embora, no procedimento da tríplice lavagem não se faça a quarta lavagem, ela faz parte do método aqui proposto, pois é esta água que fornece aos alunos a visualização da situação real da embalagem ao término de tal procedimento e que representa o resíduo de agrotóxico que está retido nas embalagens quando estas chegam aos postos de recebimentos. Esta água foi acondicionada em um frasco com os dizeres "Resíduo Final". Estes frascos contendo parte dos volumes das águas de lavagem foram comparados visualmente, em relação à coloração das caldas feitas com concentrações crescentes da formulação, que neste caso, foram representadas pela tinta latex preta (curva do kit). 
Após ser submetido ao procedimento da tríplice lavagem, o recipiente contendo a tinta fresca, que representou a embalagem contendo o agrotóxico, teve seu fundo perfurado, para não ser reutilizado.

\section{- Estabelecimento do método didático para avaliação quantitativa e qualitativa da eficiência da lavagem de embalagens vazias:}

Foi realizado um experimento para comprovar a eficiência qualitativa da metodologia descrita acima e para verificação quantitativamente o teor de traçante (tinta) presente após cada etapa da tríplice lavagem e no momento da devolução desta embalagem. A análise quantitativa foi obtida por meio da medida dada pelo parâmetro de condutividade e a análise qualitativa por meio da avaliação visual da coloração obtida nas diferentes amostras. A avaliação quantitativa é muito importante para os alunos da graduação do curso de agronomia para que tenham um dado numérico que expresse os resultados obtidos pela tríplice lavagem e não apenas um valor subjetivo como o obtido pela avaliação visual do kit acima descrito.

Para a verificação da credibilidade do método foram utilizados os seguintes materiais: quatro litros de tinta látex de cor preta, marca Suvenil (traçador) e quatro embalagens plásticas virgens de um litro semelhantes as que são usadas para armazenar sucos de laranja e garapa e que são facilmente encontradas no comércio local, 31 bequeres de $50 \mathrm{~mL}$, micropipetas de 0 a $1000 \mathrm{uL}$, pipetas graduadas de 1,5 e 10 $\mathrm{mL}, 1$ béquer graduado de $250 \mathrm{~mL}$, água destilada, condutivímetro marca adamo (Figura 2-A, C).

Inicialmente, foram construídas três curvas padrões. Para isto, obteve-se a leitura de condutividade elétrica em micro-siemens por centímetro $(\mu \mathrm{S} / \mathrm{cm})$ em amostras de tinta látex preta diluída em água nas seguintes concentrações: $100 \% ; 50 \%, 30 \%, 15 \%, 10 \% ; 5 \%, 1 \% ; 0,5 \% ; 0,1 \% ; 0,05 \% ; 0,01 \% ; 0,005 \%$; $0,001 \% ; 0,0001 \%$ e $0,0 \%$. Com estas curvas foi possível se obter a linearidade do método para as leituras. Assim, o intervalo de concentração no qual as determinações apresentam linearidade de resposta, foi avaliada com amostras de diluições do traçante em água nas concentrações de 100 a 0 $\%$. A faixa linear utilizável foi calculada pelo coeficiente de correlação (r) da curva dos calibradores (três repetições), usando-se a água destilada como o mais baixo calibrador e a tinta pura como o mais alto.

O experimento foi composto por quatro tratamentos e quatro repetições, onde os tratamentos eram as diferentes águas de lavagem e as repetições eram amostras de embalagens de 1 litro com o traçante (tinta preta) a serem submetidas à simulação do procedimento de tríplice lavagem. Assim, foi acondicionado 1 litro de tinta látex preta em cada embalagem e estas permaneceram em descanso por 24 horas. Após este período, estas embalagens foram submetidas à tríplice lavagem após terem seus conteúdos completamente esgotados conforme sugerido pela Norma NBR 13.968 (ABNT, 1997). Coletou, como descrito acima, as águas referentes a cada lavagem e mais o resíduo final (4 tratamentos). Mediu-se a $25^{\circ} \mathrm{C}$ a condutividade elétrica (CE) em micro-siemens por centímetro $(\mu \mathrm{S} / \mathrm{cm})$ das águas de cada lavagem para cada amostra. Estes valores de CE foram utilizados para estimar as concentrações de tinta (CT) para cada situação.

Paralelamente, valiou-se visualmente a coloração das caldas dos quatro tratamentos, comparandoos com as caldas de concentrações crescentes da formulação, que neste caso, foram representadas pela tinta látex preta, como verificado pela Figura 2-D. Os frascos que continham as águas referentes a cada tratamento foram acondicionados sobre os frascos contendo as diluições de tinta da curva. Portanto, foram observados os intervalos de concentração que melhor representava cada um dos tratamentos. Para fins de análise e discussão, utilizou-se sempre os valores superiores de concentração visualizado.

Para que os alunos pudessem visualizar uma possível contaminação do operador, ao realizar a tríplice lavagem, usou-se luvas nitrílicas (Figura 2-B) .

Nucleus, v.9, n.2, out.2012 


\section{RESULTADOS E DISCUSSÃO}

\section{- Considerações da aplicabilidade do kit para demonstração qualitativa da eficiência da lavagem de embalagens vazias.}

Para a demonstração da aplicabilidade do kit, inicialmente, os frascos foram dispostos em ordem decrescente de concentração da tinta para que os alunos pudessem observar visualmente a coloração obtida pela curva padrão. Posteriormente, os frascos contendo as águas da primeira, segunda, terceria e quarta lavagem, foram dispostos atrás ou entre os frascos da curva, para serem observados.

Figura 1. Concentrações decrescentes de tinta látex preta em água (A). Águas de lavagem obtidas pela operação de tríplice lavagem de uma embalagem contendo 1 litro de tinta látex preta, imediatamente após seu esvaziamento. Demonstração visual da retirada do produto (traçante) quando se realiza a tríplice lavagem (B).

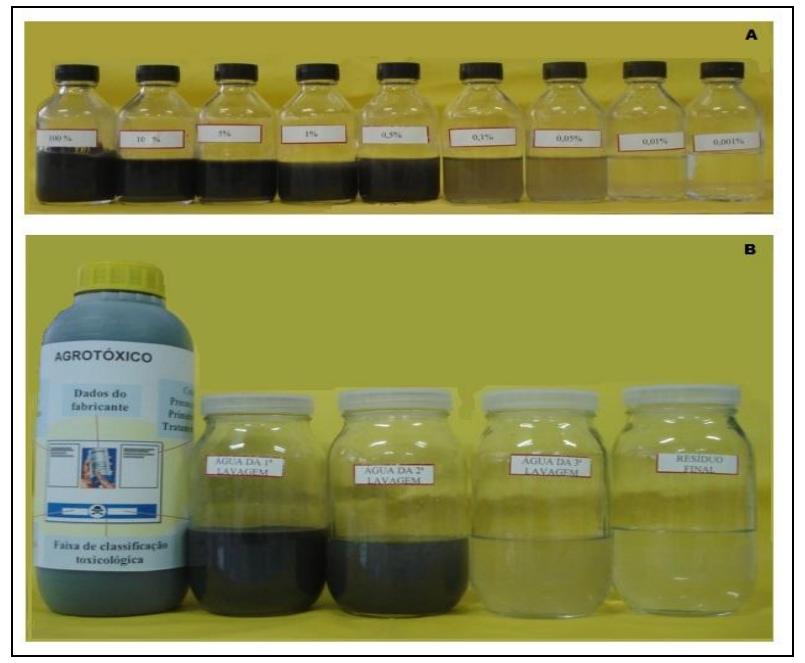

Comparando-se a intensidade da coloração das caldas de diferentes concentrações e das águas das lavagens das embalagens, pode-se estimar, aproximadamente, as quantidades de formulação que foram removidas. Verificou-se inicialmente que a primeira água de lavagem retirou a maior quantidade da formulação que fica retida internamente na embalagem recém esvaziada. De acordo com Machado-Neto (2001), a quantidade de produto que fica retida internamente na embalagem, se não for removida pela tríplice lavagem, constitui-se em uma perda financeira e fica potencialmente disponível para causar intoxicações e poluição ambiental.

Observou-se, pelo kit, que a coloração da primeira água de lavagem foi semelhante às caldas de concentrações do intervalo de $1 \%$ a $5 \%$ da formulação de tinta. Em um outro estudo, quando a tríplice lavagem foi realizada em embalagens de Gramoxone esta porcentagem foi de 3 a 6\% (MACHADONETO, 2001). Considerando-se a coloração da água da primeira lavagem semelhante à calda com $5 \%$ de tinta (Figura 1), estima-se, que cada $100 \mathrm{~mL}$ dessa água remova $5 \mathrm{~mL}$ da formulação. Como foram adicionados $250 \mathrm{~mL}$ de água na embalagem, então a primeira água provavelmente tenha removido até $12,5 \mathrm{~mL}$ da formulação, que poderia ser aproveitada na aplicação normal do produto no campo, caso a tríplice lavagem fosse realizada corretamente. Segundo Machado-Neto (2001), para o Gramoxone, considerando-se que a coloração da água da primeira lavagem foi semelhante à calda com $4 \%$, tem-se que a primeira água poderá remover até $10 \mathrm{~mL}$ da formulação. 
Desta forma, a análise visual proporcionada pelo presente kit didático foi capaz de demonstrar praticamente a eficiência e a importância da tríplice lavagem das embalagens vazias de agrotóxicos quando realizadas imediatamente após o completo esvaziamento da embalagem no campo.

Este método didático qualitativo tem sido utilizado a mais de nove anos em aulas práticas de cursos de agronomia, em programas de treinamento de trabalhadores rurais e eventos educativos para mulheres e crianças, e já foi repetido por várias vezes. A curva mantem suas características de coloração por algum tempo, e quando se verificava a mudança de coloração, era preciso preparar uma nova curva. Em todas as repetições realizadas pelos autores, o valores obtidos para a concentração da primeira água de lavagem ficaram entre 1 e $15 \%$. Já para os valores obtidos para a concentração da água obtida no resíduo final, todos ficaram visualmente abaixo de $0,01 \%$.

Observou-se que quando a tinta ficou na embalagem por longos períodos, houve aderência nas paredes da embalagem e portanto não se conseguiu que os resultados obtidos pela tríplice lavagem simulassem o que ocorreria com a formulação de um agrotóxico, o que justifica que a tinta seja colocada na embalagem 24 horas antes da realização da prática. Vale ressaltar que com o armazenamento, a tinta pode coagular e é preciso coar esta tinta para reutilizá-la na metodologia. Para isto, pode ser utilizado um pedaço de meia fina feminina como filtro. A tinta coada pode ser reaproveitada para o método didático de ensino.

Uma das vantagens, é que pode-se preparar este kit com a curva padrão qualitativa e armazená-la por um período sem que a cor se altere muito. Isto facilita o seu uso durante cursos, feiras e outros eventos de treinamento, para demonstrações visuais da eficiência da lavagem de embalagens vazias de agrotóxicos, enfatizando-se assim a importância em se realizar a operação de tríplice lavagem destes vasilhames.

\section{- Comprovação do método didático para avaliação quantitativa e qualitativa da eficiência da lavagem de embalagens vazias:}

\section{Análise quantitativa}

O método didático foi eficiente para o aprendizado dos alunos, despertando nestes o interesse pelos procedimentos realizados e sensibilizando-os da importância de se realizar este procedimento da tríplice lavagem das embalagens vazias de agrotóxicos de acordo com as recomendações técnicas.

Figura 2. Amostras das águas de lavagem de uma das embalagens contendo tinta látex preta após ser submetida à operação de tríplice lavagem (A). Demonstração visual da tinta contida na luva nitrílica após o manuseio para a realização da tríplice lavagem (B). Leitura da condutividade de uma das amostras (C). Concentrações decrescentes de tinta látex pretas (D).

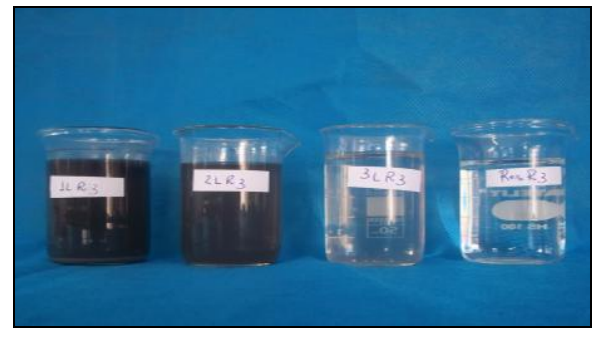

A

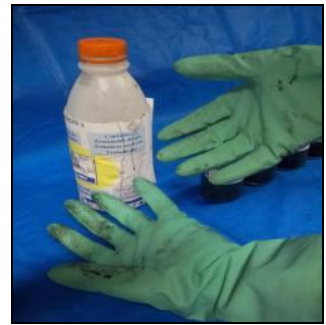

B

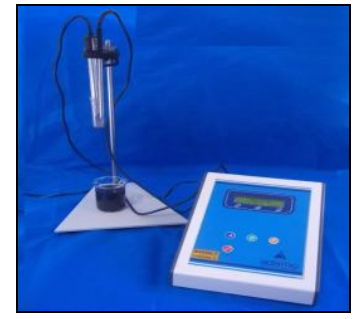

$\mathrm{C}$ 


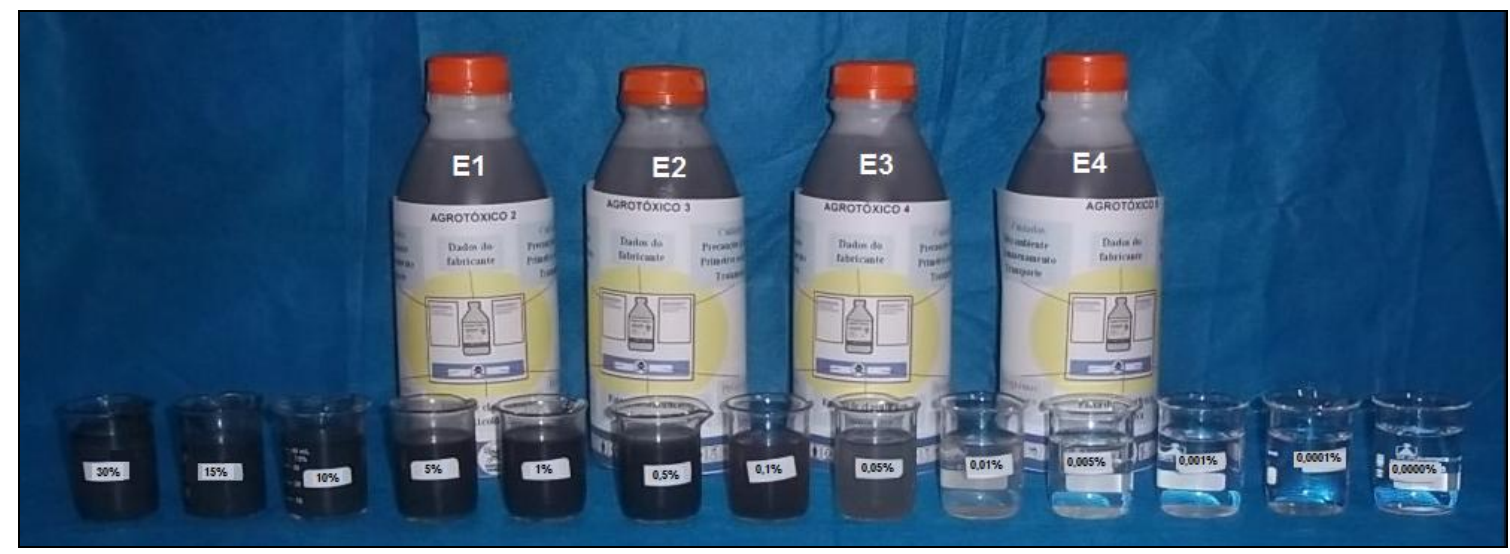

$\mathrm{D}$

O modelo ajustado estatisticamente foi o de primeira ordem. Utilizou-se um programa computacional SigmaPlot versão 2011. Neste estudo, a faixa linear foi determinada pelo coeficiente de correlação da curva dos calibradores, usando-se a concentração de $0 \%$ como o mais baixo calibrador e remoção sucessiva dos mais altos, até que fosse encontrado um coeficiente satisfatório. A faixa de linearidade de resposta para a determinação do método foi estabelecida no intervalo de concentração de 0 a $15 \%$ do traçante em água, com coeficiente de correlação $(r)$ e determinação de 0,994 e ( $r^{2}$ ) superiores à 0,988 .

A condutividade média apresentada pela tinta pura foi de $3653,3 \mu \mathrm{S} / \mathrm{cm}$ enquanto que para a água destilada foi de 104,6 $\mu \mathrm{S} / \mathrm{cm}$. As leituras de condutividade elétrica e os valores estimados das concentrações de tinta nos diferentes tratamentos estão apresentados na Tabela 1. Todas as embalagens, após serem submetidas ao procedimento de tríplice lavagem apresentaram valores inferiores a 652,4 $\mu \mathrm{S} / \mathrm{cm}$ para a primeira lavagem, resultando em concentrações de tinta menores do que $9,18 \%$. Já para a água da segunda lavagem, os valores, foram inferiores a 114,6 $\mu \mathrm{S} / \mathrm{cm}$, resultando em valores de concentração de tinta estimados menores que $0,03 \%$. Nos casos em que a ocorrência de previsões para a concentração de tinta deram negativas, estas foram consideradas iguais a zero. (Tabela 1). A curva de concentração de tinta em função da condutividade elétrica ajustada está apresentada na Figura 3.

Tabela 1. Valores estimados de concentração de tinta (CT) em \% a partir da condutividade elétrica (CE) $(\mu \mathrm{S} / \mathrm{cm})$ medida em cada tratamento. Médias, desvio padrão e coeficiente de variação dos valores de CT.

\begin{tabular}{|c|c|c|c|c|c|c|c|c|c|c|c|}
\hline \multirow{3}{*}{ Tratamentos } & \multicolumn{8}{|c|}{ Repetições } & \multicolumn{3}{|c|}{ Dados Estatísticos } \\
\hline & \multicolumn{2}{|c|}{ E1 } & \multicolumn{2}{|c|}{ E 2} & \multicolumn{2}{|c|}{ E 3} & \multicolumn{2}{|c|}{ E 4} & \multirow[t]{2}{*}{$\mathrm{M}$} & \multirow[t]{2}{*}{ DP } & \multirow[t]{2}{*}{$\mathrm{CV}(\%)$} \\
\hline & $\mathrm{CE}$ & $\mathrm{CT}$ & $\mathrm{CE}$ & $\mathrm{CT}$ & $\mathrm{CE}$ & $\mathrm{CT}$ & $\mathrm{CE}$ & CT & & & \\
\hline L 1 & 652,4 & 9,18 & 628,9 & 8,78 & 484,2 & 6,32 & 642,9 & 9,02 & 8,32 & 1,346 & 1,812355 \\
\hline L 2 & 111,6 & 0,00 & 112,6 & 0,00 & 113,0 & 0,01 & 114,6 & 0,03 & 0,01 & 0,021 & 0,000449 \\
\hline L 3 & 103,7 & 0,00 & 104,3 & 0,00 & 105,1 & 0,00 & 104,7 & 0,00 & 0,00 & 0,010 & 0,000103 \\
\hline $\mathrm{RS}$ & 103,5 & 0,00 & 104,1 & 0,00 & 104,1 & 0,00 & 104,2 & 0,00 & 0,00 & 0,005 & 0,000029 \\
\hline
\end{tabular}

E1, E2, E3 e E4= embalagens com tintas representando as embalagens de agrotóxicos (Repetições); M = Média; DP = Desvio Padrão

L1, L2, L3 e Resíduo Final (RS) = águas da primeira, segunda e terceira lavagem de cada embalagem e água residual (Tratamentos). 
Figura 3. Curva de concentração de tinta (CT) em função da condutividade elétrica (CE).

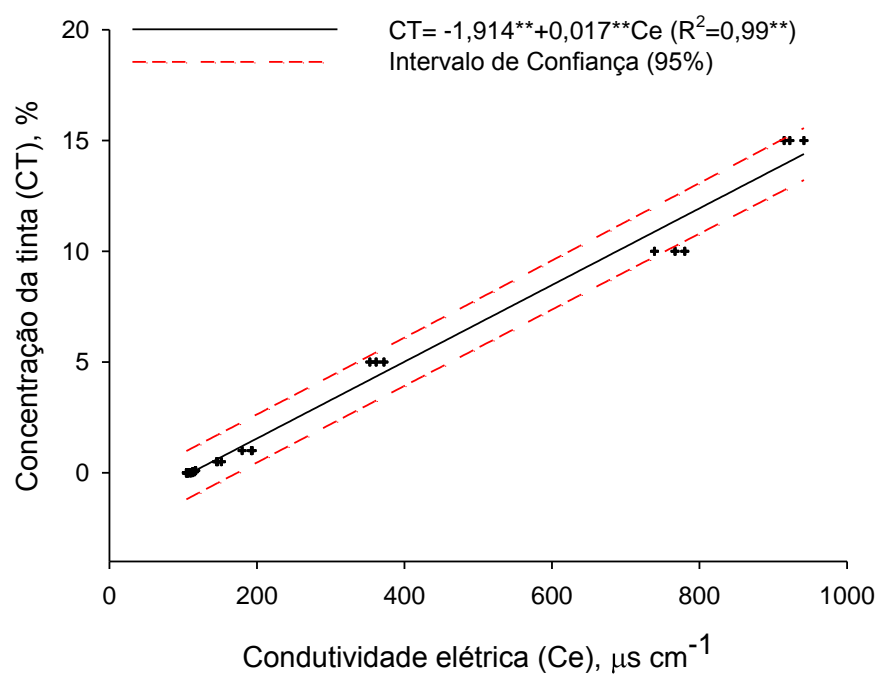

Com estes valores, torna-se mais fácil de se comprovar aos alunos a necessidade em se realizar a tríplice lavagem, uma vez que eles conseguem visualizar eficiência da tríplice lavagem através dos resultados gerados pelo experimento e plotados no gráfico. Pela curva é possível o aluno visualizar a quantidade exata de resíduo remanescente nas embalagens após as lavagens. $\mathrm{O}$ aluno pode compreender que o resíduo remanescente na embalagem (o presente, na água da quarta lavagem) é o resíduo que estará presente na embalagem no momento em que ela for devolvida pelo usuário para os postos de recebimento de embalagens vazias de agrotóxicos e posteriormente encaminhada para seu destino correto.

Qualitativamente, cada uma das repetições, foi avaliada visualmente. Verificou-se que os pontos obtidos para as águas após a terceira lavagem, em todas as embalagens foram abaixo de $0,05 \%$, e que os valores visualizados para a água residual sempre foram inferiores a 0,005\% (Tabela 2 e Figura 4). Os desvios padrões e o coeficiente de variação entre as repetições foram, respectivamente, menores que 2,5 e $6,25 \%$. Portanto, este método didático proposto é capaz de demonstrar ao aluno a eficiência do procedimento da tríplice lavagem. Segundo Catarinacho (s.d.), toda embalagem vazia tríplice lavada que apresente um resíduo líquido remanescente no seu interior inferior a $0,01 \%$ é considerada rejeito comum.

Tabela 2. Valores das leituras visuais para a concentração de tinta (CT) em \% para cada tratamento. Médias, desvio padrão e coeficiente de variação dos valores de CT.

\begin{tabular}{|c|c|c|c|c|c|c|c|}
\hline \multirow[b]{3}{*}{ Tratamentos } & \multicolumn{7}{|c|}{ Concentração Visual observada para cada tratamento ( \%) } \\
\hline & \multicolumn{4}{|c|}{ Repetições } & \multicolumn{3}{|c|}{ Dados Estatísticos } \\
\hline & E1 & $\mathbf{E} 2$ & E 3 & $\mathbf{E} 4$ & $\mathbf{M}$ & DP & $\mathrm{CV}(\%)$ \\
\hline L 1 & 15 & 15 & 10 & 15 & 13,75 & 2,5 & 6,25 \\
\hline L 2 & 0,1 & 0,5 & 0,5 & 1 & 0,525 & 0,369 & 0,136 \\
\hline L 3 & 0,01 & 0,01 & 0,01 & 0,05 & 0,020 & 0,020 & 0,000 \\
\hline $\mathrm{RS}$ & 0,005 & 0,005 & 0,005 & 0,005 & 0,005 & 0,000 & 0,000 \\
\hline
\end{tabular}

E1, E2, E3 e E4= embalagens com tintas representando as embalagens de agrotóxicos (Repetições); $\mathrm{M}=\mathrm{Média;} \mathrm{DP}$ $=$ Desvio Padrão

L1, L2, L3 e Resíduo Final (RS) = águas da primeira, segunda e terceira lavagem de cada embalagem e água residual (Tratamentos). 
Figura 4. Demonstração visual da eficiência das águas de lavagem em relação às caldas com concentrações decrescentes de tinta látex pretas.

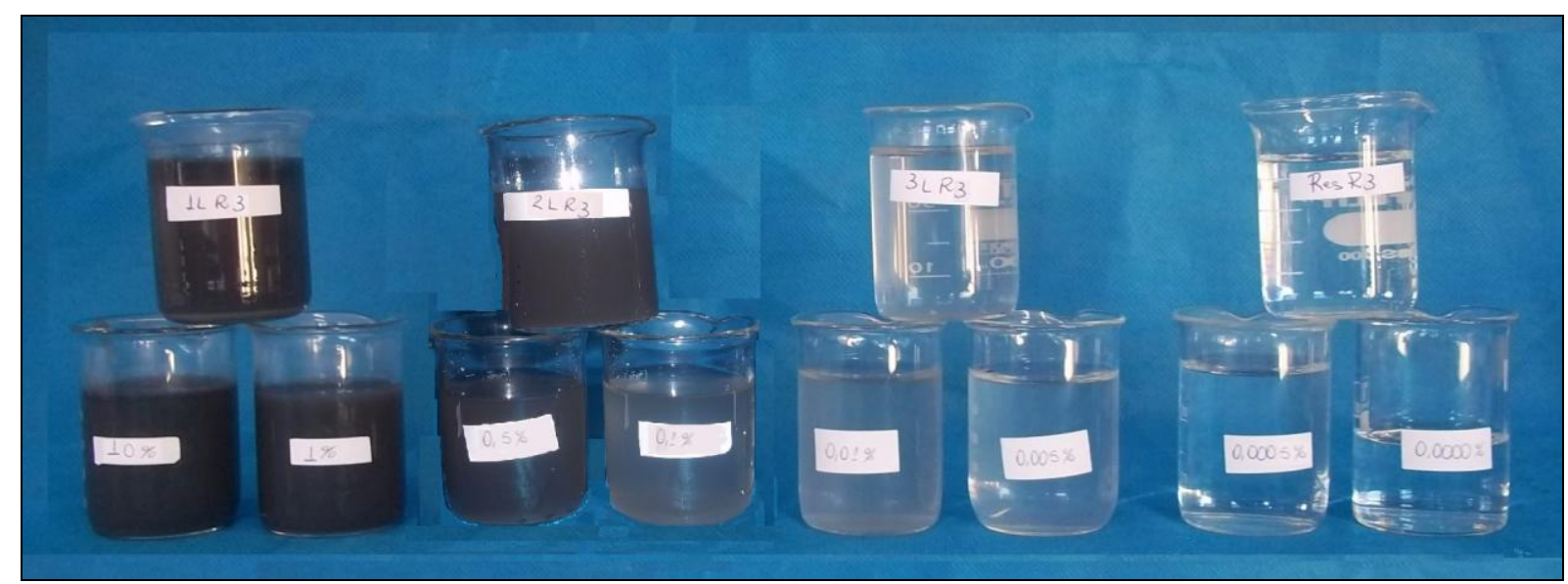

Pelas tabelas e figuras apresentadas, comprova-se a que o método com tinta látex preta é eficaz e apresenta repetibilidade para a demonstração qualitativa e quantitativa quanto à eficiencia do procedimento da tríplice lavagem.

Ainda, foi realizada a visualização da contaminação do operador ao fazer a tríplice lavagem, através da observação das manchas de tintas nas luvas do operador (Figura 2-B). É interessante que se escolha para isto dois alunos, um cuidadoso e um mais desatencioso. Geralmente, observa-se que a quantidade de tinta é mais expressiva nas luvas utilizadas por alunos mais desatenciosos, demonstrando que as atitudes do operador afetam sua exposição ao agrotóxico.

O método didático quali-quantitativo proposto, apresenta-se como uma técnica de ensinar e tem por finalidade sensibilizar e convencer o operador de que realizar a lavagem das embalagens vazias corretamente logo após seu esgotamento é de extrema importância, no sentido de garantir que os resíduos de agrotóxicos remanescentes nestas embalagens rígidas após serem tríplice lavadas estejam dentro dos níveis permitidos. Permite, de forma segura, a visualização da porcentagem do traçador (tinta) que é retirada destas embalagens e demonstra ao usuário a necessidade e vantagens em se realizar a tríplice lavagem logo após o esvaziamento da embalagem e com o máximo de cuidado possível.

\section{CONCLUSÃO}

O presente método didático é fácil de ser realizado em aulas práticas, de rápido preparo e de grande utilidade para a demonstração segura de uma metodologia já consagrada, que é a tríplice lavagem das embalagens vazias de agrotóxicos. Sua praticidade e segurança, por não utilizar agrotóxicos, possibilita que seja utilizado em escolas de ensino fundamental e médio, além de cursos de treinamento, feiras agropecuárias, dias de campo e outros eventos educativos relacionados ao uso dos agrotóxicos.

\section{AGRADECIMENTOS}

Os autores agradecem aos técnicos Gilson José Leite do Departamento de Fitossanidade da UNESP / Jaboticabal, Valmor Cláudio Raizaro do Curso de Agronomia do Centro Universitário Moura Lacerda de Ribeirão Preto, e aos assistentes de suporte acadêmico II, Adriana Kimie Kimura e Fábio 
Yamamoto da UNESP/Registro pelo apoio durante o desenvolvimento da metodologia empregada. Agradecem também aos doutores Vicente de Paula Pereira, Reginaldo Barboza da Silva, Luis Carlos Ferreira de Almeida e José Carlos Barbosa pela ajuda nas diferentes etapas do trabalho.

\section{REFERÊNCIAS}

ABNT - ASSOCIAÇÃO BRASILEIRA DE NORMAS TÉCNICAS. NBR 13968: embalagem rígida vazia de agrotóxico: procedimento de lavagem. Rio de Janeiro, 1997.

AEASP - Associação de Engenheiros Agrônomos do Estado de São Paulo. Tríplice Lavagem de Embalagens Vazias de Agrotóxicos. São Paulo, 1992. 11p.

BAPTISTA, G.C. Descontaminação, reciclagem e descarte de embalagens de agrotóxicos. NOTESALQ, Ano IV. Abril/1996, número 10.

BARREIRA, L. P.; PHILIPPI, A. J. A. A problemática dos resíduos de embalagens de agrotóxicos no Brasil. In: XXVIII Congreso Interamericano de Ingeniería Sanitaria y Ambiental, 2002, Cancún, México. Disponível em: http://www.bvsde.paho.org/bvsaidis/mexico26/iv-001.pdf, acesso em outubro de 2012.

BRASIL. DECRETO no 4.074, de 4 de janeiro de 2002. Diário Oficial [da] República Federativa do Brasil, Poder Executivo, Brasília, DF, 8 jan. 2002. Seção 1.

BRASIL. LEI no 7.802, de 11 de julho de 1989. Diário Oficial [da] República Federativa do Brasil, Poder Executivo, Brasília, DF, 12 jul. 1989. Seção 1, p. 11459/60.

CATARINACHO, J. Destino final das embalagens de produtos fitossanitários. ANDEF. s.d. In: http://www.biologico.sp.gov.br/rifib/IIIRifib/117-119.pdf; acesso em 02 de abril de 2009.

CHIQUETTI, S. C. Eficiência da Tríplice Lavagem em unidades de recebimento de embalagens de agrotóxicos. Campinas, 2005. Dissertação de mestrado (Mestrado em Engenharia Civil: Saneamento e Ambiente) - Faculdade de Engenharia Civil, Arquitetura e Urbanismo, Universidade Estadual de Campinas, UNICAMP.

EVARISTO A.; BAPTISTA, G.C. de; MACIEL, E. Efeito da tríplice lavagem na contaminação residual de embalagens de pesticidas II - aldrin e deltametrina. In: CONGRESSO BRASILEIRO DE ENTOMOLOGIA, 14., 1993, Piracicaba. Anais... Piracicaba: Sociedade Entomológica do Brasil, 1993.

GERASSI, P. V. M. (elaboradora). Manual de destinação final de embalagens vazias de produtos fitossanitários. São Paulo: AEASP - Associação dos engenheiros agrônomos do estado de São Paulo; MMA/FNMA - Ministério do meio ambiente / Fundo Nacional do Meio Ambiente; ANDEF - Associação Nacional de Defensa Vegetal, Agosto de 1998. Disponível em:

http://www.cepis.org.pe/muwww/fulltext/resipeli/destinac/destinac.html; acesso em 02 de abril de 2009.

Importância da tríplice lavagem e da lavagem sob pressão. In: Produção Rural. Julho 2000. Disponível em: http://www2.uol.com.br/campogrande/producao/noticias/triplice1.htm . Acesso em:13 jun. 2011.

IPT/CEMPRE. Lixo Municipal: Manual de gerenciamento integrado. 2.ed. São Paulo: IPT/CEMPRE, 2000.

MACHADO NETO, J.G, Segurança no trabalho com agrotóxicos em cultura de eucalipto. Jaboticabal: Funep, 2001. 117p.

MOREIRA, J. Et al. Avaliação integrada do impacto do uso de agrotóxicos sobre a saúde humana em uma comunidade agrícola de Nova Friburgo. Ciencia e Saúde coletiva. v. 7, p.299-311. Rio de Janeiro, 2002. 
PAVARINI, G. M. P. Segurança nas aplicações de agrotóxicos. In: Uso Correto e Seguro dos Agrotóxicos: programa UCorSA. Registro: Universidade Estadual Paulista; Campus Experimental de Registro, 2008. p 2850. ISBN 978-85-98187-23-5.

PEREIRA, R. E. A.; GALDIANO, L. C. Elaboração do perfil de agricultores nas culturas de soja e milho, utilizando o método FAFRAM, em Ituverava-SP e região. Nucleus: Revista Científica da Fundação Educacional de Ituverava. v. 02, n. 1, p. 31-34, 2004.

PRIOTTO, M. A. Alternativa de destino para embalagens usadas de Glifosato. Curitiba, 2007.

Dissertação (Mestrado em Desenvolvimento de Tecnologia) - Instituto de Tecnologia para o

Desenvolvimento - LACTEC. $103 \mathrm{f}$. Disponível em:

<http://www.lactec.org.br/mestrado/dissertacoes/arquivos/MarcioPriotto.pdf > . Acesso em: 01 ago. 2012.

SUGIMOTO, LUIZ - Agricultor lava mal as embalagens de agrotóxicos - Jornal da Unicamp - Ed 298 - Agosto de 2005 - Disponível em: <http://www.unicamp.br〉. Acesso em: 09 abr. 2012.

ZAMBOLIN, L; CONCEIÇÃO, M. Z.; SANTIAGO, T. O que os engenheiros agrônomos devem saber para orientar o uso de produtos fitossanitários. 2 ed. Viçosa: UFV, 2003. 376p. 